\title{
Layered Metal Composites: Newest Generation of Radiation-Protective Materials
}

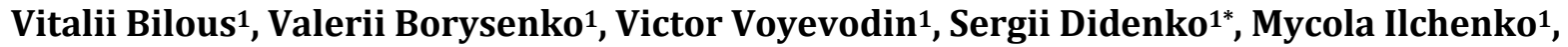 \\ Olexander Rybka1, Olexander Kuznetsov'², Yurii Plisak ${ }^{2}$ \\ ${ }^{1}$ National Science Center "Kharkiv Institute of Physics and Technology", Kharkiv, Ukraine \\ ${ }^{2}$ Scientific and Production Group "Dniprotekhservice", Dnipropetrovsk, Ukraine \\ Email: sudid@mail.ru
}

Received 30 May 2014; revised 15 June 2014; accepted 12 July 2014

Copyright (C) 2014 by authors and Scientific Research Publishing Inc.

This work is licensed under the Creative Commons Attribution International License (CC BY).

http://creativecommons.org/licenses/by/4.0/

c) (i) Open Access

\section{Abstract}

The expediency of development of one of the newest highly effective radiation-protective materials-layered composites of "light metal/heavy metal" type is substantiated. The characteristics of the internal architecture of composites of $\mathrm{Al} / \mathrm{Pb}$ type made by consecutive application of vacuum and normal atmospheric rolling are adduced. The differences between the radioisotope and accelerating techniques of experimental testing of radiation-protective properties of materials are described. The results of the testing of composites and the influence of their structure on radiation-protective properties of the investigated materials are characterized. It is shown that the radiation-protective efficiency of composites certain structures may be $30 \%-40 \%$ higher than the aluminum. This gives the opportunity to reduce the weight of radiation-protective structure at preservation of effectiveness of protection at aluminum level, or to increase the effectiveness of protection at constant weight of this structure.

\section{Keywords}

Radiation-Protective Materials and Structures, Al/Pb Layered Composites, Methods and Test Results of Radiation-Protective Properties, Radiation-Protective Efficiency

\section{Introduction}

One of the challenges faced by developers of new generations of spacecrafts (SC) is to increase the level of their ${ }^{*}$ Corresponding author.

How to cite this paper: Bilous, V., Borysenko, V., Voyevodin, V., Didenko, S., Ilchenko, M., Rybka, O., Kuznetsov, O. and Plisak, Y. (2014) Layered Metal Composites: Newest Generation of Radiation-Protective Materials. Journal of Materials Science and Chemical Engineering, 2, 6-11. http://dx.doi.org/10.4236/msce.2014.28002 
reliability in the long stay in extraterrestrial environments. Among the many different factors that determine this characteristic of the SC, perhaps the most important is the resource of non-failure operation of on-board equipment and devices.

Previously, it was found that various electronic devices fail in space significantly more often and faster than their analogues in terrestrial conditions. This is because in orbit these devices are under the influence of ionizing radiation in which the main sources are the galactic cosmic rays, solar wind and belts van Allen.

Today, there are two approaches to the problem of reduction of influence of radiation-induced effects on the functional characteristics of on-board electronics. The first is the development of radiation-resistant semiconductor materials and electronic devices on their basis [1]. The second focuses on the creation of new radiationprotective (RP) materials and radiation-protective structures of them integrated in the design of SC. This approach, not as an alternative to the first, has a more General nature, as allows reducing radiation load both on electronic devices and other on-board objects of SC, primarily on biological objects.

It should be noted that a rather significant weight and dimensional characteristics of radiation-protective structures, which are widely applied in various terrestrial stationary objects (nuclear power plants, storage of radioactive waste, isotopic sources of ionizing radiation, etc.), due to low efficiency of traditional homogeneous RP materials. Therefore you can't use the analogues of known structures for the protection of various mobile objects (SC, aircraft, mobile nuclear power installations, etc.).

Thus, the exhaustion of the opportunities to create new highly effective radiation-protective structures on the basis of traditional homogeneous materials is one of the urgent problems of modern material science. Perspective direction of its overcoming is the creation of layered structures consisting of separate layers of two (or more) homogeneous materials with different atomic number $Z$. The association in one of heterogeneous structure of substances with small and big $\mathrm{Z}$ creates conditions for repeated reflection of particles and the gammas from the layers contact surfaces of these substances and the return of photons in layers filled with highly absorbing material not going beyond the outer limits of the structure.

Due to its specific constitution, this structure is a kind of a trap for photons and therefore has a higher protective properties in comparison with homogeneous materials of which it consists. This is a consequence of the fact that scattering and absorption mechanisms at the atomic level inherent in homogeneous materials, in heterogeneous structures are summarized with additional other mechanisms. Such mechanisms are caused by peculiarities of the internal structure of layered composites, i.e. their internal architecture.

Results of the analytical research of the evolution of the characteristics of photon flux of x-ray and gammaradiation [2] and high-energy electrons [3], which occur in layered structures, showed that the criterion of the best materials for multilayer structures is the maximum difference of the coefficients of reflection of the neighboring layers. To this criterion correspond light and heavy metals with small and big Z, respectively.

The high practical relevance of research in the field of creation of RP composites shows the cost of the launch of $1 \mathrm{~kg}$ load into orbit: from $\$ 3000 \ldots 5000$ (low orbit) up to $\$ 30,000$ (high orbit). Consequently, reducing weight large-tonnage apparatus at $100 \ldots 200 \mathrm{~kg}$ will significantly reduce its cost and/or give possibility to increase the weight of the payload to perform the main functional purpose of the device.

\section{Methods and Materials}

Radiation-protective efficiency (RPE) of layered composites and their homogeneous components was evaluated on the degree of decrease of density of a stream of electrons and gamma-rays that have passed through the tested sample. The value of this density was measured using a detector of ionizing radiation (IR) in the form of crystal of semiconductor compound CdZnTe connected to the measuring system. Relative measurement error is $5 \%$.

We used two independent methods, namely: accelerating (the first technique that was used at the stage of preliminary studies of a small number of samples) and radioisotope (second technique that was used at the stage of main research of large number of samples). The peculiarity of the first methodology is the use of electrostatic electron accelerator, which generate monochromatic beam of electrons with energy of $2.5 \mathrm{MeV}$.

According to the second method radioisotope ${ }^{90} \mathrm{Sr}+{ }^{90} \mathrm{Y}$ source of electrons was used. This source emits electrons with a continuous energy spectrum in the range from several tens $\mathrm{\kappa eV}$ to several MeV. Owing to this, the second technique provides a more realistic conditions of radiation load of samples in comparison with the first method. Besides, time and electric power expenses for preparation and testing of one sample by the second method is less. Therefore, we used the first method for testing small number of samples at the stage of preliminary studies and for selective verification of the data obtained at the stage of main research by the second method. 
Aluminum $\left(\mathrm{Z}_{\mathrm{Al}}=13\right)$ and lead $\left(\mathrm{Z}_{\mathrm{Pb}}=82\right)$ were chosen as components for laminated composite of "light metal /heavy metal" type. It should be noted that low-alloyed aluminum alloys are materials which are widely used in the construction of various SC and because of that we compared composites RPE with aluminum. For manufacturing of composites of $\mathrm{Al} / \mathrm{Pb}$ type we have applied the methodology, which provides for the consistent application of vacuum rolling and conventional airy rolling [4]. Vacuum rolling was used for welding layers of $\mathrm{Al}$ and $\mathrm{Pb}$, and airy rolling was used for obtaining strips of various thicknesses of composites and homogeneous $\mathrm{Al}$ and $\mathrm{Pb}$.

Necessity of reception of strips of different thickness is caused by that correct comparison of RPE materials of different composition and structure is possible only at use samples which have the same surface density $\chi$. This material characteristic is equal to the product of the volumetric density $\rho$ of specific stripes on its thickness $\mathrm{h}$ [5] [6]. Therefore, affect the value $\chi$ of plate of certain material with the density of $\rho$ is only possible by changing its h. Note that this characteristics is very important for comparative analysis of different materials RPE: $\chi$ is the weight of the plate plot of thickness $\mathrm{h} \mathrm{cm}$ from a material with a volumetric density of $\rho \cdot \mathrm{g} / \mathrm{cm}^{3}$, which has an area of $1 \mathrm{~cm}^{2}$.

Other important characteristics of composite of $\mathrm{Al} / \mathrm{Pb}$ type are number of its layers, the sequence of their location and the total volume fraction of all Pb layers in composite $\alpha_{\mathrm{Pb}}$, the value of which can be $0<\alpha_{\mathrm{Pb}}<1$.

All samples that were used for preliminary testing RPE with the use of accelerator techniques (see Table 1) had $\chi=0.5 \mathrm{~g} / \mathrm{cm}^{2}$. For the main phase of testing with use of radioisotope techniques have been made three series of five-layer composite stripes $\mathrm{Al} / \mathrm{Pb} / \mathrm{Al} / \mathrm{Pb} / \mathrm{Al}$ with various volume fractions of lead $\alpha_{\mathrm{Pb}}$ namely $0.16,0.45$ and 0.30 arbitrary units (Figure 1). For obtaining samples of composites and homogeneous $\mathrm{Al}$ and $\mathrm{Pb}$ with different values of $\chi$ in the range of $0.1<\chi<0.55$ were rolled strips of thicknesses from 0.1 up to $1.86 \mathrm{~mm}$ with such external dimensions: width $-80 \ldots 100 \mathrm{~mm}$, length $-250 \ldots 300 \mathrm{~mm}$. Several tens of research disc samples of $40 \mathrm{~mm}$ in diameter were cut out from these stripes.

\section{Prepare Your Paper before Styling}

Estimation of the samples RPE was obtained from comparison value of IR stream density W measured experimentally both when the sample was located between the IR source and detector ${ }^{\mathrm{ON}} \mathrm{W}$, and in the absence of a sample ${ }^{\mathrm{OFF}} \mathrm{W}$. For the comparative analysis of these values obtained for materials of various structures, the reduction ratio ${ }^{\mathrm{d}} \mathrm{K}$ of the primary beam density in the sample was used. This factor was calculated by formula:

$$
{ }^{\mathrm{d}} \mathrm{K}=1-{ }^{\mathrm{ON}} \mathrm{W} /{ }^{\mathrm{OFF}} \mathrm{W}
$$

The value of this ratio is measured in relative units from 0 (in case of absence of the sample, i.e. ${ }^{\mathrm{OFF}} \mathrm{W}={ }^{\mathrm{ON}} \mathrm{W}$ ) up to 1 (the case of the presence of a hypothetical sample, completely opaque for IR, i.e. ${ }^{\mathrm{ON}} \mathrm{W}=0$ ).

Parameters of the internal architecture of samples used at the stage of preliminary testing and data concerning their RPE are shown below (Table 1). In the last column of the table the relationship of RPE of composites and aluminum for which ${ }^{\mathrm{d}} \mathrm{K}_{\mathrm{Al}}=0.46$ is shown.

To facilitate analysis of obtained experimental results and formulation of conclusions, it is conditionally separable investigated composite samples in two groups: the first—samples \# 1 and 2 with asymmetric structure, the second-samples \# 3 and 4 with symmetrical structure.

Samples of the first group were cut out from the same composite strip, but turned towards the incident beam by layer of light metal (sample \# 1, "light/heavy" scheme) or by heavy metal (sample \# 2, "heavy/light" scheme) have demonstrated different RPE. Experimentally established fact benefits scheme "light/heavy" compared with the scheme "heavy/light" is consistent with the results of the analytical research [3]. This allows to assume that the increasing the number of layers (i.e. the number of interfaces "light/heavy") can increase composites RPE at constant volume concentration of heavy metal in them.

A similar comparison of the results for samples of the second group is impossible, because the volume fractions of lead in them are different. At the same time, it is possible to speak about increase composites RPE with the increase of volume fraction of lead in them.

Giving a comprehensive assessment of the samples of the second group, it should be noted that the ${ }^{\mathrm{d}} \mathrm{K}$ value for the sample \# 3 is less than for the sample \# 4, but composite of this type has advantages compared to other investigated composites. First, the outer layers of aluminum ensure a high corrosion resistance and eliminate contact of toxic lead with the environment. Secondly, we can predict that its mechanical properties will be higher than that of the composite of the same symmetric type (sample \# 4), which not only has a greater RPE, but 
Table 1. Characteristics of the internal architecture and radiation-protective efficiency of samples for preliminary testing.

\begin{tabular}{cccccc}
\hline $\begin{array}{c}\text { Sample } \\
\#\end{array}$ & $\begin{array}{c}\text { The scheme of the } \\
\text { structure }\end{array}$ & $\begin{array}{c}\text { The thickness of the } \\
\text { sample, mm }\end{array}$ & $\begin{array}{c}\text { Volume fraction of lead, } \alpha_{\mathrm{Pb}} \\
\text { Reduction ratio, }{ }^{\mathrm{d}} \mathrm{K}_{\mathrm{i}}\end{array}$ & ${ }^{\mathrm{d}} \mathrm{K}_{\mathrm{i}} /{ }^{\mathrm{d}} \mathrm{K}_{\mathrm{Al}}$ \\
\hline 1 & $\mathrm{Al} / \mathrm{Pb}$ & 1.15 & 0.19 & 0.68 & 1.48 \\
2 & $\mathrm{~Pb} / \mathrm{Al}$ & 1.15 & 0.19 & 0.66 & 1.43 \\
3 & $\mathrm{Al} / \mathrm{Pb} / \mathrm{Al} / \mathrm{Pb} / \mathrm{Al}$ & 1.00 & 0.27 & 0.69 & 1.50 \\
4 & $\mathrm{~Pb} / \mathrm{Al} / \mathrm{Pb} / \mathrm{Al} / \mathrm{Pb}$ & 0.78 & 0.44 & 0.79 & 1.58 \\
\hline
\end{tabular}

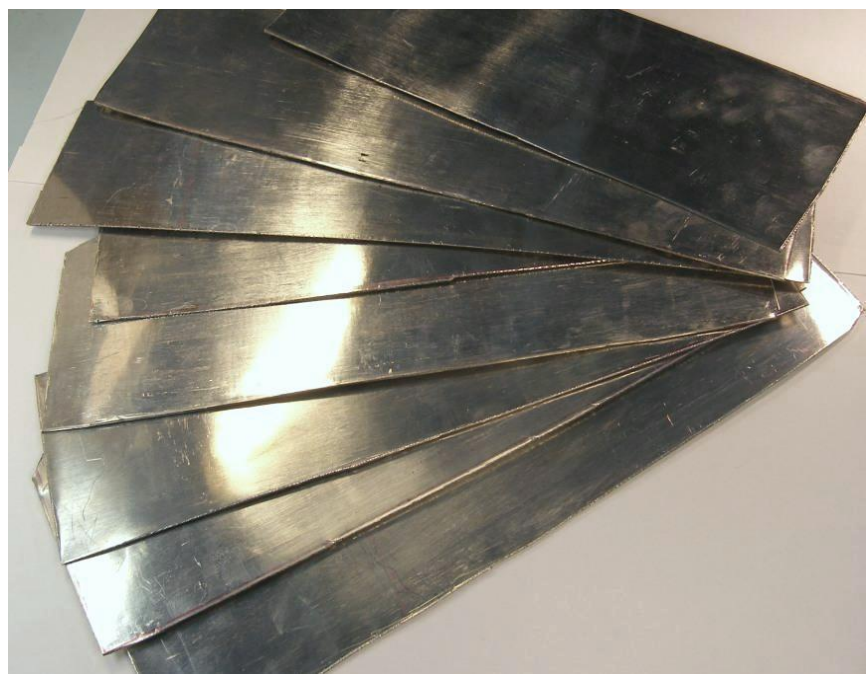

Figure 1. Five-layer composite stripes $\mathrm{Al} / \mathrm{Pb} / \mathrm{Al} / \mathrm{Pb} / \mathrm{Al}$ with various volume fractions of lead coefficient strips.

also contains a greater volume fraction of not strong lead.

So, at the stage of preliminary testing experimentally several important facts were established. First, it was obtained experimental confirmation of theoretical predictions of higher RPE of layered composites compared to their homogeneous components. Secondly, it is shown that at equal values of surface density $(\chi=0.5)$ RPE of composites significantly exceeds the characteristics of its components and is different for composites which has a different scheme of their structure. These indicate of that the composites are inherent to the phenomenon of RPE sensitivity to the parameters of their internal architecture.

The results of preliminary testing of layered $\mathrm{Al} / \mathrm{Pb}$ type composites prompted us to extend the range of studied composites $\mathrm{Al} / \mathrm{Pb} / \mathrm{Al} / \mathrm{Pb} / \mathrm{Al}$, namely to make composites with various volume fractions of lead $\alpha_{\mathrm{Pb}}$ and surface density $\chi$.

Testing RPE of these composites have been conducted with the use of radioisotope techniques and provides a wide array of experimental data (Figure 2). General characteristic of these data is that the value of the coefficient of reduction ${ }^{\mathrm{d}} \mathrm{K}$ increases with increasing values of surface densely $\chi$ for all investigated materials, as well as with increasing volume fraction of lead $\alpha_{\mathrm{pb}}$ in composites.

Graphics ${ }^{\mathrm{d}} \mathrm{K}=\mathrm{f}\left(\chi, \alpha_{\mathrm{Pb}}\right)$ have complex nonlinear form. RPE of lead is more than that of aluminum [5] [6], so curve ${ }^{d} \mathrm{~K}=\mathrm{f}(\chi)$ for lead lies above the curve for aluminum in all investigated interval of values of $\chi$. Between these curves there are located curves for composites in the sequence, which corresponds to the values $\alpha_{\mathrm{Pb}}$ in them. Increased lead content in composite corresponds to closer location of its curve to curve for lead.

In general case among the materials which have the same values of ${ }^{\mathrm{d}} \mathrm{K}$ the most effective is material that has the smallest value of $\chi$, i.e. the lowest weight of plot with an area of $1 \mathrm{~cm}^{2}$. For quantitative demonstration of advantages of weighting and dimensional characteristics of composites in comparison with Al, we have selected three fixed values of ${ }^{\mathrm{d}} \mathrm{K}_{\text {const }}$ : 0.75, 0.85 and 0.95. From the graphs ${ }^{\mathrm{d}} \mathrm{K}=\mathrm{f}\left(\chi, \alpha_{\mathrm{Pb}}\right)$ (Figure 1 ) were defined values of surface density $\chi_{\mathrm{Al}}$ for aluminum and $\chi_{\mathrm{i}}$ for composites with various values of lead $\alpha_{\mathrm{Pb}}=0.16,0.30$ and 0.45 which correspond to the selected values of ${ }^{\mathrm{d}} \mathrm{K}_{\text {const. }}$. Next, we calculated the ratio $\chi_{\mathrm{Al}} / \chi_{\mathrm{i}}$ and the ratio of values of thickness of composite and aluminum samples $\mathrm{h}_{\mathrm{Al}} / \mathrm{h}_{\mathrm{i}}$ (Table 2). 


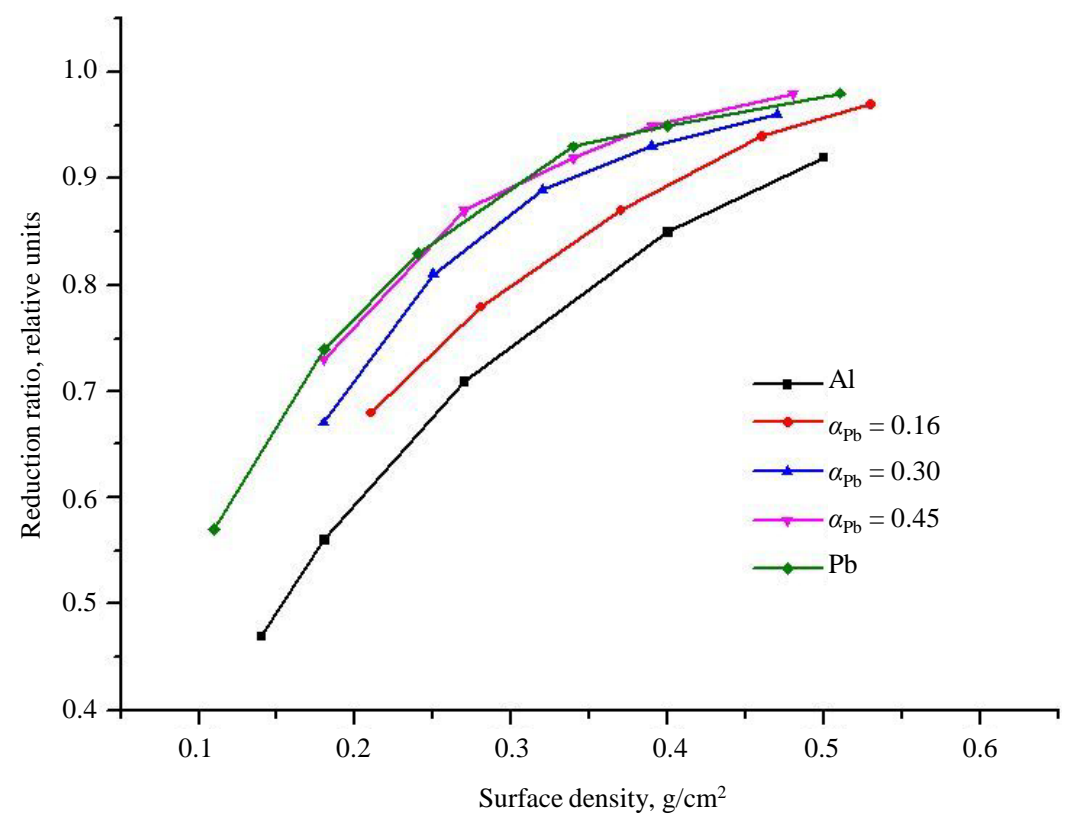

Figure 2. The reduction ratio of ionizing radiation stream density ${ }^{\mathrm{d}} \mathrm{K}$ dependence on the surface density $\chi$ of homogeneous materials and of composites with different volume fraction of lead $\alpha_{\mathrm{Pb}}$.

Table 2. The ratio $\chi_{\mathrm{Al}} / \chi_{\mathrm{i}}$ and $\mathrm{h}_{\mathrm{Al}} / \mathrm{h}_{\mathrm{i}}$ for selected values ${ }^{\mathrm{d}} \mathrm{K}_{\mathrm{i}}$.

\begin{tabular}{|c|c|c|c|c|c|c|c|}
\hline${ }^{\mathrm{d}} \mathrm{K}_{\text {const }}$ & $\chi_{\mathrm{Al}}, \mathrm{g} / \mathrm{cm}^{2}$ & $\alpha_{\mathrm{Pbi}}$ & $\chi_{\mathrm{i}}, \mathrm{g} / \mathrm{cm}^{2}$ & $\chi_{\mathrm{Al}} / \chi_{\mathrm{i}}$ & $\mathrm{h}_{\mathrm{Al}}, \mathrm{mm}$ & $\mathrm{h}_{\mathrm{i}}, \mathrm{mm}$ & $\mathrm{h}_{\mathrm{Al}} / \mathrm{h}_{\mathrm{i}}$ \\
\hline & & 0.16 & 0.26 & 1.19 & & 0.65 & 1.76 \\
\hline \multirow[t]{3}{*}{0.75} & 0.31 & 0.30 & 0.22 & 1.41 & 1.15 & 0.42 & 2.77 \\
\hline & & 0.45 & 0.18 & 1.72 & & 0.27 & 4.21 \\
\hline & & 0.16 & 0.35 & 1.14 & & 0.88 & 1.69 \\
\hline \multirow[t]{3}{*}{0.85} & 0.40 & 0.30 & 0.29 & 1.38 & 1.48 & 0.55 & 2.71 \\
\hline & & 0.45 & 0.26 & 1.54 & & 0.39 & 3.76 \\
\hline & & 0.16 & 0.47 & 1.17 & & 1.18 & 1.73 \\
\hline \multirow[t]{2}{*}{0.95} & 0.55 & 0.30 & 0.44 & 1.25 & 2.04 & 0.83 & 2.45 \\
\hline & & 0.45 & 0.39 & 1.41 & & 0.59 & 3.45 \\
\hline
\end{tabular}

\section{Conclusions}

Experimental verification of theoretical predictions about higher radiation-protective efficiency of laminated composite of $\mathrm{Al} / \mathrm{Pb}$ type in comparison with aluminum has been obtained. It is shown that at equal values of surface density of composites and aluminum radiation-protective efficiency of composites exceeds this characteristic of aluminum by $30 \%-40 \%$. At the same coefficient of diminution of ionizing radiation, the composites have significantly smaller values of weight and thickness compared to aluminum. It is established that the composites are inherent to the phenomenon of sensitivity of the radiation-protective efficiency to the parameters of their internal architecture, i.e. the dependence on the scheme of the structure of composites.

A comparison of the dependences of radiation-protective efficiency of composites of $\mathrm{Al} / \mathrm{Pb}$ type, from both the applied methods of radiation-protective efficiency testing, demonstrates the full qualitative coincidence of these dependencies. However, quantitative comparison of data obtained by these methods is not possible because of differences of types of ionizing radiation energy spectra and the methods of its stream density registration.

Chosen algorithm of estimation of radiation-protective efficiency of composites in comparison with aluminum enables to determine main parameters of the internal architecture of radiation-protective composites of $\mathrm{Al} /$ 
$\mathrm{Pb}$ type (surface density and volume fraction of lead), which provide a given value of the coefficient diminution of ionizing radiation, or to predict the level of radiation-protective efficiency of a composite material with the given values of the surface density and volume fraction of lead.

\section{References}

[1] Korshunov, F.P., Bogatyrev, Yu.V. and Vavilov, V.A. (2006) Effect of Radiation on Integrated Circuits. Science and Technology, Minsk.

[2] Bilous, V.A., Komarov, A.O. and Shilyaev, B.A. (2008) Protective Multilayer Thin Film Shields from X-Ray and Gamma Radiation. Problems of Atomic Science and Technology, 7, 202-204.

[3] Borts, B.V., Marchenko, I.G. and Bezdomny, P.N. (2009) Simulation of Passage of Electrons through Layered Composite Material. Problems of Atomic Science and Technology, 4-7, 175-177.

[4] Voyevodin, V.M., Didenko, S.Yu. and Ilchenko, M.I. (2010) Prospects for Production and Use of Metal Multilayer Composites Received by Vacuum Rolling. Problems of Atomic Science and Technology, 5, 89-94.

[5] Mashkovich, V.P. (1982) Protection from Ionizing Radiation. Energoatomizdat, Moscow.

[6] Aleshin, A.A. and Sarkisov, V.S. (1981) Power Nuclear Reactors. Sudpromgiz, Leningrad. 
Scientific Research Publishing (SCIRP) is one of the largest Open Access journal publishers. It is currently publishing more than 200 open access, online, peer-reviewed journals covering a wide range of academic disciplines. SCIRP serves the worldwide academic communities and contributes to the progress and application of science with its publication.

Other selected journals from SCIRP are listed as below. Submit your manuscript to us via either submit@scirp.org or Online Submission Portal.
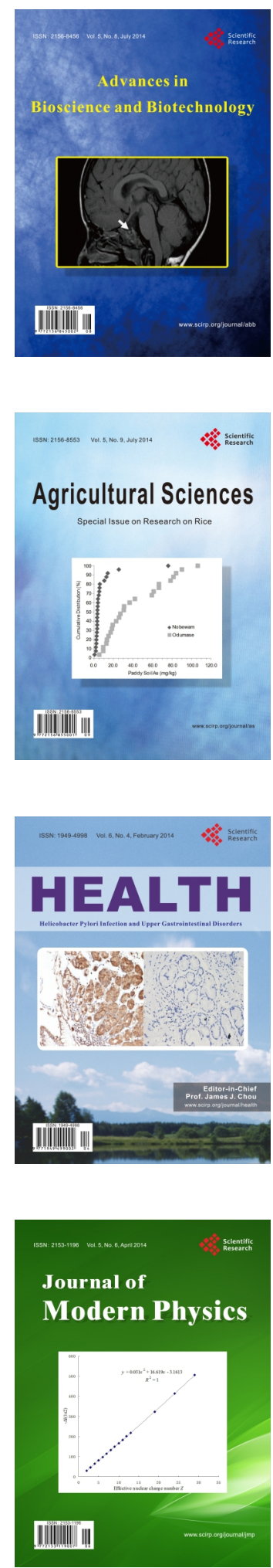
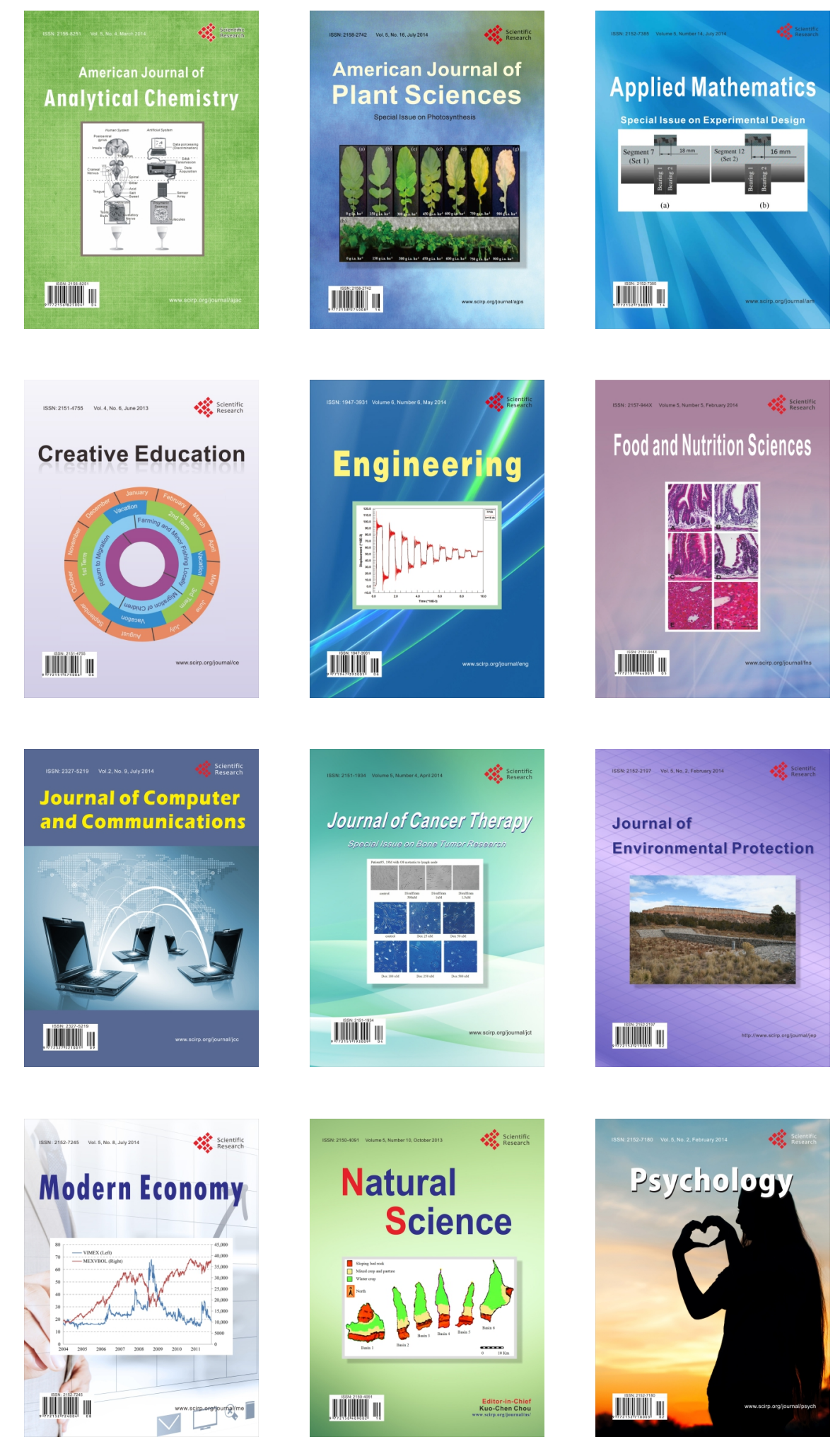